\section{PTH-94 DRIM EXPRESSION IN COLORECTAL CANCER AND ITS POSSIBLE TUMOUR SUPPRESSIVE ROLE, CLINICAL AND PROGNOSTIC SIGNIFICANCE}

Xuefei Dong, yuxin Cui ${ }^{*}$ xuefei Dong. Cardiff university, Cardiff, UK

\subsection{6/gutjnl-2021-BSG.297}

Introduction DRIM (Down Regulated in Metastasis Protein) is a protein found to be reduced or lost in metastatic cancer cells and has subsequently been found to be identical to Small Subunit Processome Component (UTP20). It is known to be key to ribosomal RNA (rRNA) processing. However, it is primarily present in the nucleus and cell membrane which suggests to link to gene expression and also membrane related cell function. This strongly suggests that it has an important role to play in cancer cell functions. The present study describes our findings on the expression of DRIM in colorectal cancer and its clinical relevance in disease progression and outcome.

Methods The DRIM/UTP20 protein was assessed on a human colon tissue array by immunohistochemistry. The DRIM/ UTP20 gene transcript was quantitatively analysed by real-time quantitative polymerase chain reaction(RT-PCR) in a cohort of fresh frozen colorectal tumours and matched normal mucosal tissues. The median follow-up period of the cohort was 6 years.

Results Colon tissues were stained strongly for DRIM protein and the staining was largely confined to the cytoplasmic and membrane region of the cells. Normal mucosal cells showed stronger staining than colon cancer cells. Patients who had high levels of DRIM had a significant longer overall survival (OS) $(138 \pm 9.4$ months) than those with low levels $(70 \pm 13.2$ months) $(p=0.026)$, with the survival rate respectively for those with high and low levels at $77.2 \%$ and $46.6 \%$ during the follow-up period. Likewise, patients with high DRIM levels had a highly significant longer disease-free survival (DFS) compared with those with low levels $(p<0.01)$. The hazard ratios for OS and DFS were respectively 0.332 and 0.272 , suggesting a positive predictor of DRIM expression for a favourable overall and disease survival outcome. Although patients who developed distant metastasis had low levels of DRIM compared with those without metastatic diseases, the difference is not statistically significant $(p=0.26)$. When examining the clinical and pathological factors of the patients, it was found that there was a progressive reduction of DRIM from $\mathrm{T} 1$ tumours to $\mathrm{T} 4$ tumours $(\mathrm{p}=0.002)$ and reductions from TNM1 to TNM4 tumours $(\mathrm{p}=0.031$, by ANOVA). Similarly, levels of DRIM in Dukes A tumours (90980 \pm 55541 copies) were also higher than Dukes B $(40243 \pm 22456)$ and Dukes C $(19151 \pm 660)$ tumours. DRIM expression did not correlate with lymph node involvement of this cohort of colorectal cancers.

Conclusion DRIM/UTP20 is strongly expressed in colon tissues. The expression levels of this molecule in colon cancer tissues are a favourable factor for the clinical outcome of patients, suggesting a prognostic value of the molecule in colon cancer.

\section{PTH-95 RELATIONSHIP BETWEEN FAECAL CALPROTECTIN AND RISK OF FUTURE COLORECTAL NEOPLASIA}

Yong Fai Kong*, Fiona Ross, Campbell SD Roxburgh, Donald C McMillan, Paul G Horgan, James H Park. Academic Unit of Surgery, University of Glasgow, Glasgow Royal Infirmary, Glasgow, UK

\subsection{6/gutjnl-2021-BSG.298}

Introduction Current British Society of Gastroenterology guidelines (Rutter et al. 2020) recommend surveillance colonoscopy at three years for patients with high-risk polyp findings on index colonoscopy. However, less than half of patients will have subsequent polyps identified, and even fewer patients will subsequently develop colorectal cancer. As such, current surveillance strategies remain to be improved upon. Faecal calprotectin (FC) is a marker of intestinal inflammation, and has been shown to be associated with the presence of colorectal carcinoma and advanced adenomas. However, whether FC may be used to identify patients at high risk of future colorectal neoplasia beyond index polypectomy remains unknown. The present study examined the relationship between FC concentration at the time of index colonoscopy and risk of future colorectal neoplasia, in patients found to have colorectal adenomas within the Scottish Bowel Screening Programme.

Methods Patients were identified from a prospective study of local and systemic inflammatory responses in patients undergoing screening colonoscopy in NHS Greater Glasgow and Clyde (REC number:15/WA/0053). Patients included underwent screening colonoscopy between January 2016 and June 2017 with adenomas identified on index colonoscopy. FC was collected prior to commencement of bowel preparation, and categorised as $<50 \mu \mathrm{g} / \mathrm{g}$ (undetectable), $50-200 \mu \mathrm{g} / \mathrm{g}$ or $>200$ $\mu \mathrm{g} / \mathrm{g}$ (clinically relevant). Outcome data, including subsequent colonoscopies, were recorded retrospectively. Subsequent colonoscopy findings were categorised as normal, polyp, cancer, inflammatory or other pathology. Relationship between FC concentration and risk of future colonoscopy and risk of future colorectal neoplasia (adenoma, advanced adenoma or cancer) was examined.

Results 179 patients with adenomas were included; 44\% $(n=79)$ had a subsequent colonoscopy. $30 \%$ of patients had FC $50-200 \mu \mathrm{g} / \mathrm{g}$, and $20 \%$ had FC $>200 \mu \mathrm{g} / \mathrm{g}$; there was no association between FC concentration and risk of future colonoscopy $(P=0.384)$. On subsequent colonoscopy, 36 patients (20\%) had a further polyp and 1 patient had colorectal cancer. There was no association between elevated FC concentration and risk of adenoma $(P=0.745)$ or advanced adenoma $(P=0.490)$. The one patient with subsequent cancer had FC $>200 \mu \mathrm{g} / \mathrm{g}$.

Conclusions Although the present results are limited by the small number of patients undergoing subsequent colonoscopy within this observational study, the present results suggest that FC is not a useful marker to stratify risk of subsequent neoplasia in patients diagnosed with colorectal adenomas within a bowel screening programme. 